\section{Design Evaluation in Novel Orthoses for Patients with Medial Knee Osteoarthritis}

\author{
Khosravi M. ${ }^{1 \oplus}$, Arazpour M.. ${ }^{2,3}$, Saeedi H. ${ }^{4}$, Rezaei M.., $5 * \odot$
}

\begin{abstract}
Osteoarthritis of the knee is a debilitating condition affecting increasing numbers of individuals each year. One option for treatment is orthotic knee braces, but a little independent reviews have taken place to date on their relative outcomes for users. This study therefore evaluates the efficacy of different types of knee orthoses (braces) with regard to key aspects of use, including gait parameters, mobility and levels of comfort and compliance in subjects presenting with osteoarthritis $(\mathrm{OA})$ of the knee. The collated data is presented with relevant supporting literature and appropriate descriptions in relation to each knee orthosis type that was identified, within appropriate subsections with advantages and disadvantages appropriately allocated. An analysis of each brace as presented by the corresponding article is then described further in terms of the design and structure, user outcomes and assessment summaries. According to the study carried out in this paper, it is presented and proved that applying the use of knee braces can reduce the knee adduction moment (KAM), but the amount of reduction afforded varies between designs. All of the studies reported significant pain reduction and functional improvement with the use of a knee brace, although their effect on the knee joint range of motion vary. Knee braces long-term use depends upon high levels of comfort and patient compliance, and further studies need to be conducted on larger numbers of subjects over greater time periods to reflect the long-term outcomes accurately.
\end{abstract}

Citation: Khosravi M, Arazpour M, Saeedi H, Rezaei M. Design Evaluation in Novel Orthoses for Patients with Medial Knee Osteoarthritis . $J$ Biomed Phys Eng. 2019;9(6):719-732. https://doi.org/10.31661/jbpe.v0i0.965.

Keywords

Osteoarthritis, Knee; Adduction Moment; Gait; Knee Orthoses; Braces

\section{Introduction}

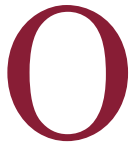

steoarthritis (OA) is a relatively common chronic condition, associated with wearing and tearing the large joints, that often occurs in the knee [1]. It is particularly prevalent in the elderly, as joint deterioration increases over time, and it is also linked to the excessive loading on the joints caused by obesity [2]. OA is a debilitating condition, causing deformation and pain that can limit daily activities in affected individuals $[3,4]$ and its prevalence is expected to double in the next decade [2]. Treatment often requires long-term interventions, including the use of knee braces, which aim to support the knee and reduce the loading on the affected joint [5].

The disease process associated with the knee. OA commonly leads to alignment anomalies of the affected lower limb during walking, that can exacerbate the existing condition [5]. Changes in the alignment of the hip, knee, and ankle joints can influence the loading that occurs within the knee $[6,7,8]$. During stance phase, for example, an increase in the knee adduction moment (KAM) caused by knee OA can lead to further loads being imparted on the affected areas, leading to more OA, and
${ }^{1} \mathrm{MSc}$, Students Research Committee,

University of Social Wel-

fare and Rehabilitation

Sciences, Tehran, Iran

${ }^{2}$ PhD, Pediatric Neurore-

habilitation Research

Center, University of

Social Welfare and

Rehabilitation Sciences,

Tehran, Iran

${ }^{3} \mathrm{PhD}$, Orthotics and

Prosthetics Department,

University of Social Wel-

fare and Rehabilitation

Sciences, Tehran, Iran

${ }^{4} \mathrm{PhD}$, Orthotics and

Prosthetics Department,

Iran University of Medi-

cal Sciences, Tehran,

Iran

${ }^{5} \mathrm{PhD}$, School of Rehabilitation, Shahid Beheshti University of Medical Sciences, Tehran, Iran

*Corresponding author: M. Rezaei

Orthotics and Prosthet-

ics Department, Iran

University of Medical

Sciences, Tehran, Iran

E-mail: rezaei.to@gmail.

com

Received: 17 June 2018

Accepted: 10 July 2018 
more pain and reduced mobility $[6,9,10,11]$.

There are a number of treatment options available for knee OA, in addition to knee bracing [12] Surgical interventions include the knee arthroplasty, tibia osteotomy and fusion (if knee arthroplasty is not successful), but this type of treatment is relatively expensive and it can lead to further complications [13] Consequently, non-surgical treatment is often the first choice, with an immediate aim of preventing further deterioration and improving function and mobility [14]. Non-surgical treatments of knee OA typically include the use of pain relief medications (NSAIDs), glucosamine, hyaluronic acid injections, physiotherapy, and the use of braces as orthotic interventions. New studies have shown that steroid injections can relieve the pain for up to two years. Hyaluronic acid can also be used, but it is only usually effective in mild cases of OA [15]. In addition, appropriate drugs can have unwanted side effects and may not help to relieve all the symptoms of discomfort [16].

By contrast, orthotic intervention, is a relatively low risk method of relieving symptoms. In addition to the use of knee braces, insoles can be fitted on the affected side with a lateral wedge to counteract the adduction moment [17-19]. With a similar aim, but a different technique, knee braces are designed to remove weight from the affected compartment by applying a varus or valgus moment, (depending on the compartment involved). Therefore, potentially reducing forces on the affected side [20]. Knee braces can be prefabricated (off the shelf) or custom made; Draganich and colleagues compared prefabricated and custommade braces and concluded that the custommade orthoses reduced pain more effectively than prefabricated orthoses, by reducing the knee varus angle and adduction moment during walking and stair climbing [21].

Patient compliance with the use of knee braces has been the subject of review, with Giori et al. concluding that $20 \%$ of people abandoned their orthosis during the first 6 months of treatment, and $29 \%$ after 12 months. Of the remaining subjects, only $73 \%$ wore the brace to the end of their treatment [16]. In addition, although OA is more common in women than men [22], the men continue to wear knee braces more often than women [23].

The relatively bulky designs of some knee orthoses are considered to be factors in the device non-usage that they are recorded for less than 3 hours per day [24]. An uncomfortable fit, combined with awkward designs and limited adjustability, are also quoted as limiting factors with regard to usage [25]. Many knee orthoses are constructed from metal, thermoplastic or composite materials. Although they offer the means to offload the knee joint, their inherent rigidity and intimate fitting can lead to prolonged discomfort over longer periods $[26,27]$. The key requirements therefore for any successful knee orthoses treatment would be a device that enabled comfortable usage over time, but one that also provided the necessary loading capabilities, and adjustability, to offset and reduce any unwanted moments around the knee.

Consequently, This investigation reviews the existing literature around the treatment of OA with different types of knee braces, and attempts to classify and report on the respective success of each orthosis type, with appropriate evidence and independent evaluation.

\section{Gaasbeek et al / 'SofTec' brace \\ Design and Structure}

The so-called SofTec OA brace was designed and manufactured by Gaasbeek and colleagues in 2006 . The brace includes a lateral hinge that incorporates an air bladder, which can be inflated by the user to apply a changeable valgus force (Figure 1). The brace has four non-elastic straps, with two located one on the thigh and two more on the lower leg, creating an appropriate three-point pressure system, with each pair being attached in opposition; the use of the straps permits fine adjustment and controls and resists any rota- 

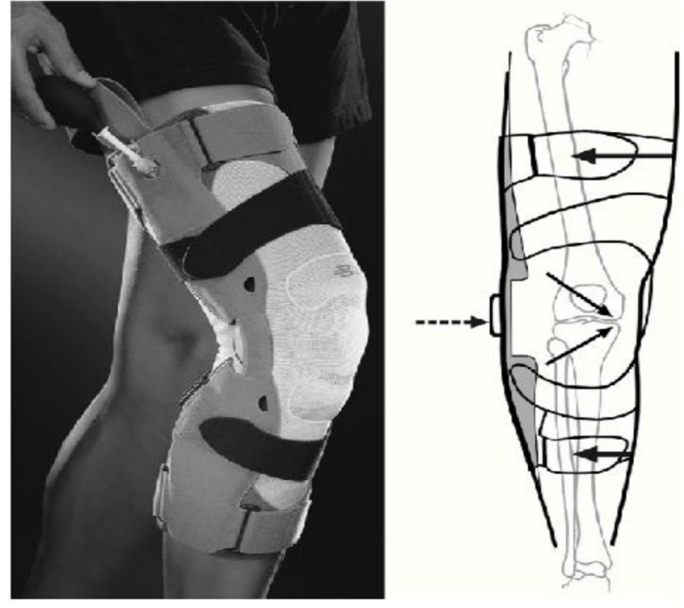

Figure 1: The SofTec OA valgus brace. On the left: air chamber inflation with a bulb pump to adjust brace valgus force and on the right: schematic three-point mechanism producing valgus [24].

tional forces. After donning, the air bladder is simply inflated by the user until the symptoms of arthritis are improved. To help to improve comfort, silicone pads are positioned between the air bladder and the surface of leg [28, 29].

User Outcomes

The use of the SofTec OA brace has been shown in order to improve walking speed, and reduce pain (pain scores without brace: $6.8 \pm$ 2.5; with brace: $4.7 \pm 3.0, \mathrm{P}=0.03$ ). Function is improved and symptoms of OA based on the WOMAC score are also reduced (without brace: $50.1 \pm 17.6$, with brace: $63.0 \pm 18.4, \mathrm{P}=$ $0.01)$. No significant differences in foot progression angle have also been observed, but step lengths are shorter compared to non-use $(p=0.017$ and $p<0.001)$. The knee range of motion (ROM) may be reduced significantly $(p=0.02)$ due to step length limitation, with knee extension significantly decreased, but again this has no apparent detrimental effect on walking speed [28, 29].

Assessment Summary

Knee ROM and step length are both reduced when to walk with this orthosis, due to the prevention of full knee extension. The design enables a large counter moment to be created around the knee, thereby reducing knee varus deviation significantly, making it more effective in people with severe OA. In addition, it can also prevent increasing amounts of knee varus in mid-stance [28, 29]. However, the design is based around a pump system, which may over time be prone to failure; in addition, the device relies on effective alteration by the user.

Stamenovic et al / pneumatic knee brace

\section{Design and Structure}

This brace again works in combination with pneumatic control, but uses neoprene sleeves in combination with straps to prevent brace displacement and resist rotation. Three air bladders made of latex are included in the design, and are positioned on the inner side of the straps, with two of the bladders located medially with the respect to the knee, and one laterally, thereby effectively creating a 3-point pressure system around the knee when to be inflated. The strapping is made of nylon, which is relatively light, but strong enough to impart the force exerted by the bladders, and produce the required abduction moment. Because the bladders are inside straps and the elasticity index of straps (nylon $10^{3} \mathrm{Mpa}$ ) is more than bladders (latex $10^{\circ} \mathrm{Mpa}$ ), parts of straps which bladder is under them and the rest of the straps have identical mechanical properties. There is more tension in socks and less tension in straps. This discrepancy is due to the different material and elasticity indices mentioned above, which enables corrections (Figure 2) [12].

\section{User Outcomes}

This type of pneumatic knee brace has been shown so as to control effectively and restrict the adductor moment in virtually all male subjects and in up to $90 \%$ in female subjects, making it potentially suited to preventing OA progression [12]. 

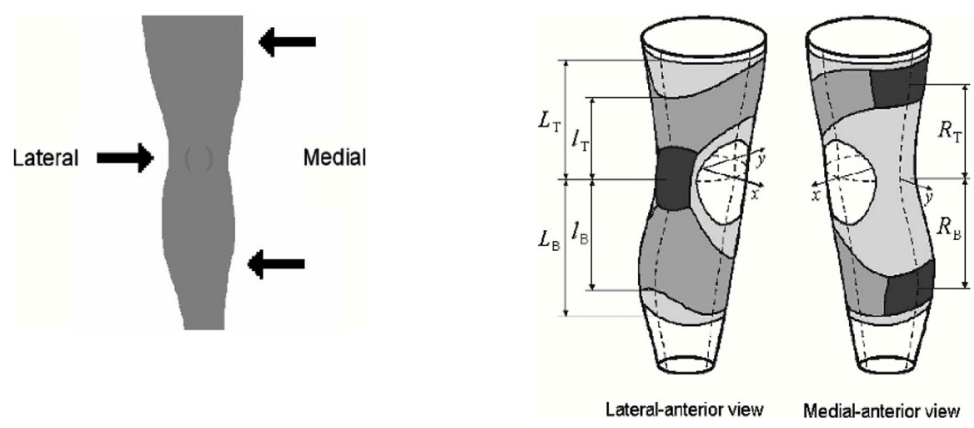

Figure 2: A schematic depiction of the front view of the leg with a three point bending system of forces [12].

\section{Assessment Summary}

To avoid displacement of brace, the user should adjust it regularly. Although the greatest amount of loading was produced by the superior-medial bladder, actual discomfort was more noticeable on the lateral side. Changing the materials, and particularly the elastic modulus, of the straps and the socks worn over the skin could help to correct this, by enabling the tension to be equalized between both materials, hence there is a reduction in rubbing between their surfaces [12]

\section{Schmalz et al/ Genu arthro brace Design and Structure}

The Genu Arthro prefabricated knee brace was created by schemalz et al, in 2010 and it consists of separate thigh and lower leg sections connected by external struts. Four straps are employed to secure the device to the user; two on the thigh and two on the lower leg respectively. The brace is available in different sizes, with the best fit selected according to the appropriate measurements; further adjustment can also be made (Figure 3 ) via the thigh section. The reaction force delivered to assist the knee will be proportional to the thigh section applied. The most important adjustment, i.e. the compensatory valgus force can be altered by the user. This brace also has a long-lever arm and low-profile foot stirrup which prevent proximal and distal migration from the orthosis during usage (Figure3) [30].

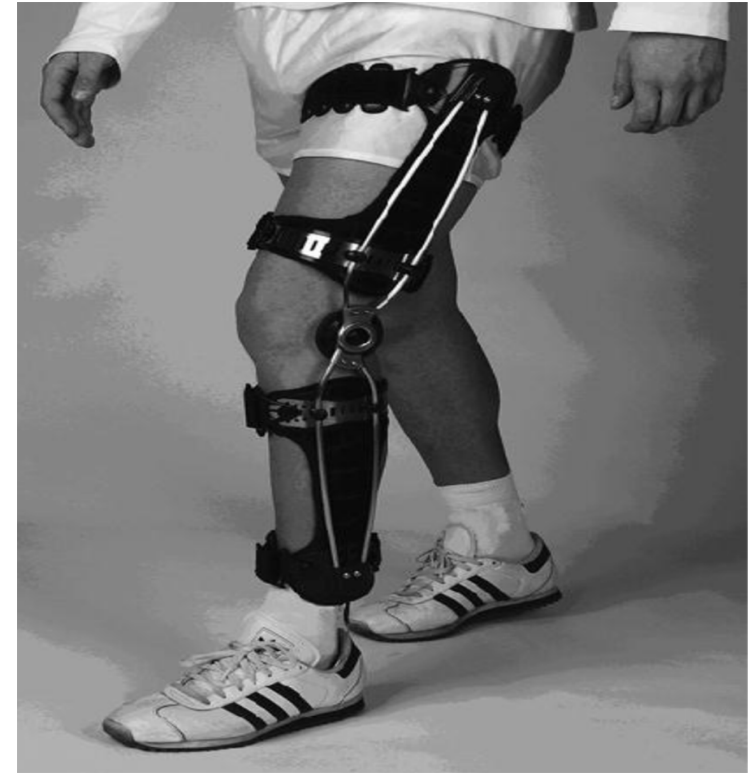

Figure 3: Genu Arthro valgus-inducing knee brace [25].

\section{User Outcomes}

This brace has been shown in order to decrease pain significantly (based on VAS scale; first week: $6.4 \pm 1.7$, fourth week: $3.3 \pm 1.9$, $\mathrm{P} \leq 0.01$ ) and improve walking speed (without brace: $1.27 \mathrm{~m} / \mathrm{s}$, with brace: $1.36 \mathrm{~m} / \mathrm{s}, \mathrm{P}$ $\leq 0.01)$. Cadence also increased significantly (without brace: $107 \mathrm{steps} / \mathrm{min}$, with brace: 110 steps/min, $\mathrm{P} \leq 0.01)$. Stride length on the affected knee also increased but not significantly (without brace: $0.71 \mathrm{~m}$, with brace: $0.73 \mathrm{~m}$ ). The step length on the healthy side is reduced 
(without brace: $0.75 \mathrm{~m}$, with brace: $0.73 \mathrm{~m}$ ), but the KAM reduction was not noticeable [30].

\section{Assessment Summary}

Relatively high-average comfort scores of between 4.3 (good) and 4.9 (very good) and long user make this brace a good choice for subjects with OA. However, some users note that the brace had a tendency to slip with respect to the thigh during use [30].

\section{Johnson et al/Ortho Pro Knee brace Design and Structure}

The Ortho Pro Knee brace was presented firstly by Johnson and colleagues in 2012 and consists of a pneumatic knee joint with active swing-assist. An elastic band is embedded within the hinge of the brace, which provides a dampening effect during knee flexion, and works in combination with the pneumatic active swing-assist during extension, provided by two air bladders. These bladders can be inflated until the desired active pressure has been achieved, and can also increased or decreased by the user according to the requisite activity level (Figure 4) [31].

\section{User Outcomes}

The use of this brace has been shown to reduce pain from a grade 7 to a grade 4 on a VAS scale. In addition, Sf36 scores were improved from a mean of 38 points to a mean of 40 points $(p=0.04)$. Improved, more natural gait parameters have also been reported, including knee ROM, walking speed and knee angle on heel strike. Walking speed for example improved from a mean of $100 \mathrm{~cm} / \mathrm{s}$ to $112 \mathrm{~cm} / \mathrm{s}$, knee ROM increased from 44 to 48 degrees, and the knee angle at heel strike was reduced from a mean of 9 degrees to a more reasonable 6 degrees. Importantly, the KAM was also reduced by $8 \%$ in all users (before brace: 0.4115 $\mathrm{nm} / \mathrm{kg}$, after brace: $0.186 \mathrm{~nm} / \mathrm{kg}$ ) [31].

Assessment Summary

This brace is relatively light, and has a flexible design that allows for greater levels of user comfort and adjustability [31].
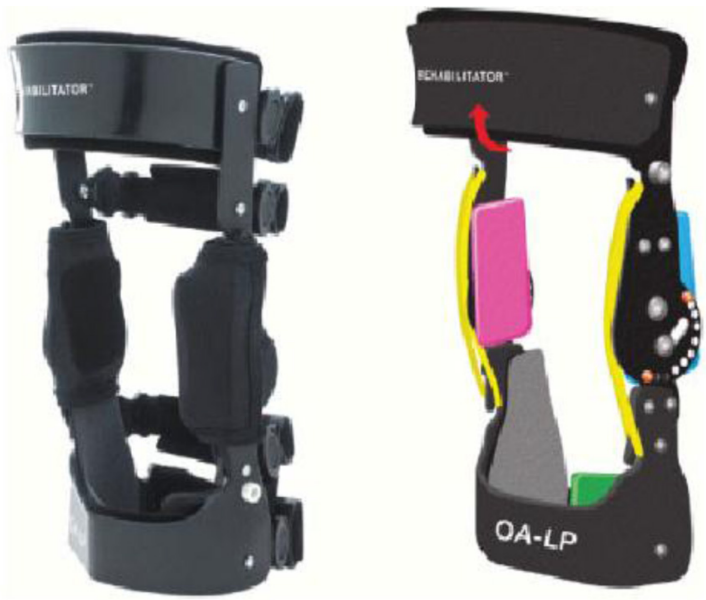

Figure 4: Ortho Pro OA Brace (Pinellas Park, $\mathrm{FL})$.

Note: the strategically placed pneumatic air bladders that allow for patient-directed offloading of the knee. Additionally, the "active swing-assist" consists of an elastic band within the hinge on both the medial and lateral aspect of the brace [26].

\section{Karimi et al (a)/un-named brace Design and Structure}

This original brace was created by Karimi and colleagues in 2012 and consists of thigh and lower leg sections, with each one consisting of an outer shell made from high density polyethylene, and an inner, adjustable shell made from low density polythene. Again, straps are employed to secure both sections, but there are also a series of adjustable screws which enable the user to actively adjust the contact pressures provided by each section. A polycentric orthotic knee joint is also included and the modular structure of the brace enables adjustment in both coronal and sagittal planes (Figure 5) [32].

\section{User Outcomes}

The KAM has been shown to significantly decreased while walking with this brace in situ, with improved medio-lateral knee alignment in two user subjects. There was no significant difference noted between the vertical force applied on the leg in the first subject, although it was significant in the second subject 


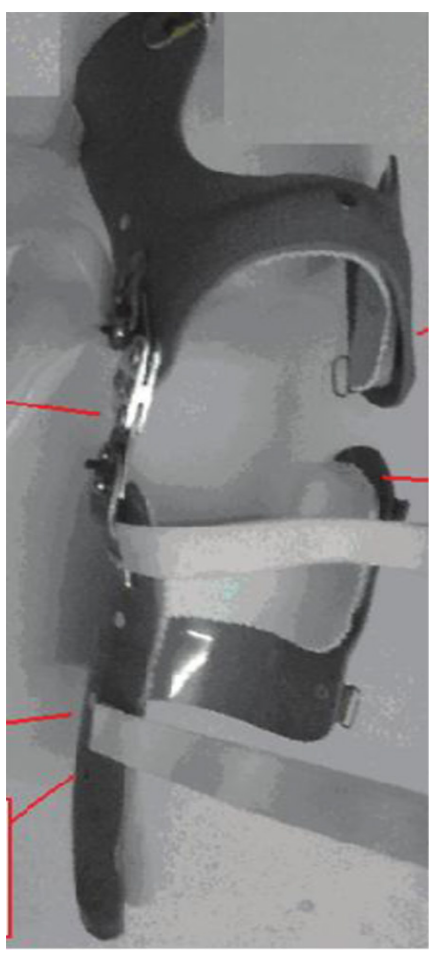

Figure 5: The new design of the knee orthosis designed for patients with knee OA [27].

$(p=0.001)$. The knee ROM did not decrease during walking, but knee instability decreased significantly [32].

\section{Assessment Summary}

This brace has a bespoke modular structure that allows a good deal of adjustment, and would therefore suit users who would not normally be easy to fit with an orthotic brace due to challenging alignment variations. The corrective load around the knee can be altered according to individual requirements. In addition, knee instability in the frontal plane is reduced and the displacement of brace during use is not significant (thanks to the security afforded by the elastic straps) [32].

\section{Della Croce et al/ The modified knee} brace (OA Lite)

\section{Design and Structure}

The modified knee brace (OA Lite) was created by Della Croce et al. in 2013 and is very similar to the brace presented by Gassbeek in 2006. The OA Lite brace has three air blad- ders, two medial and one lateral, which creates a suitable 3-point pressure system around the knee during use and after inflation. A lateral strut contains the lateral air bladder between itself and a strap. The straps are made from nylon (Figure 6), and the dimensions of each bladder are significant $(10 \times 10 \mathrm{~cm})$, with each capable of providing a pressure of 7 Psi (48 $\mathrm{kPa})$ [33].

\section{User Outcomes}

This brace affords an approximate reduction of $7.6 \%(p=0.02)$ of the KAM without bladder inflation, increasing to $26 \%$ reduction

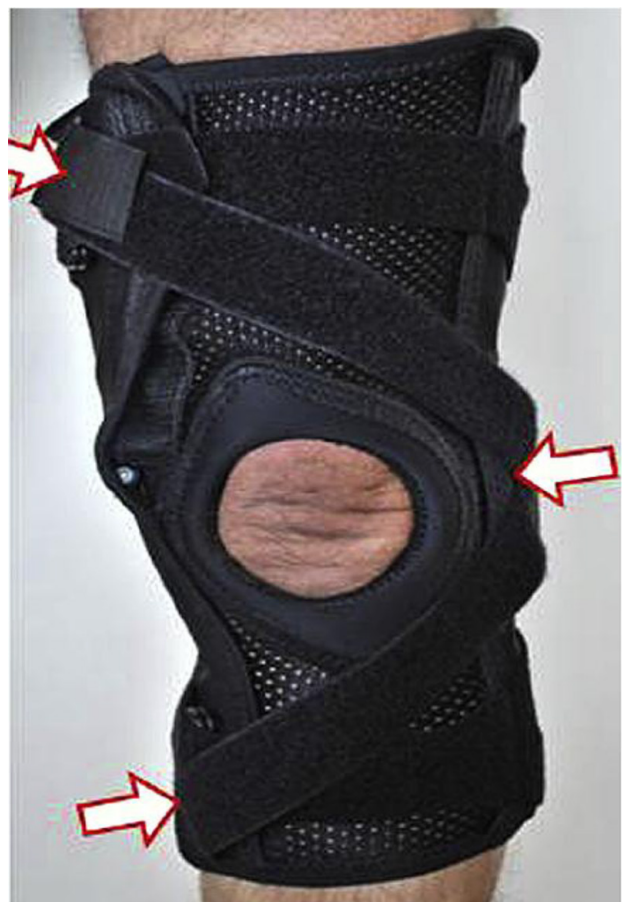

Figure 6: The modified knee brace (OA Lite) used in the study worn by a subject on the left leg. The arrows point approximately at the center of the air bladders. The arrows are also indicative of the 3-point leverage provided by the bladders, in combination with the strapping system, which acts to unload the medial compartment of the knee. The top medial bladder is firmly attached to the inner side of the sleeve and diagonal straps, the bottom medial bladder is attached to the inner side of the sleeve and diagonal straps, and the lateral bladder is firmly attached to the sleeve and sandwiched between the knee and the hinge [28]. 
$(p<0.01)$ with inflation. Pain reduction in the un-inflated condition was significantly lower than unbraced condition but there was no statistical difference in pain between unbraced and 7 psi condition [33].

Assessment Summary

This brace is off-the-shelf and not custommade, making it easily accessible for most users [33].

Arazpour et al /Bespoke pneumatic knee brace unloader

Design and Structure

A bespoke pneumatic unloader knee brace was designed and built by Arazpour et al. in 2014. The brace consisted of a medial and lateral side member, two lateral pneumatic pads (on the lower thigh and proximal of tibia) manufactured in nylon (Figure 7) and a detachable air pump. When the pneumatic pads are inflated, a valgus moment is created and applied via a 4-point pressure system. The adjustability afforded by the design enables the user to gain a comfortable, corrected knee position [34].

User Outcomes

This brace increased walking speed significantly $(\mathrm{p}=0.001)$, but this was still less than a healthy subject of similar age. The KAM was significantly reduced $(\mathrm{p}=0.001)$ by almost $7 \%$; previous studies reported a $10 \%$ reduc-
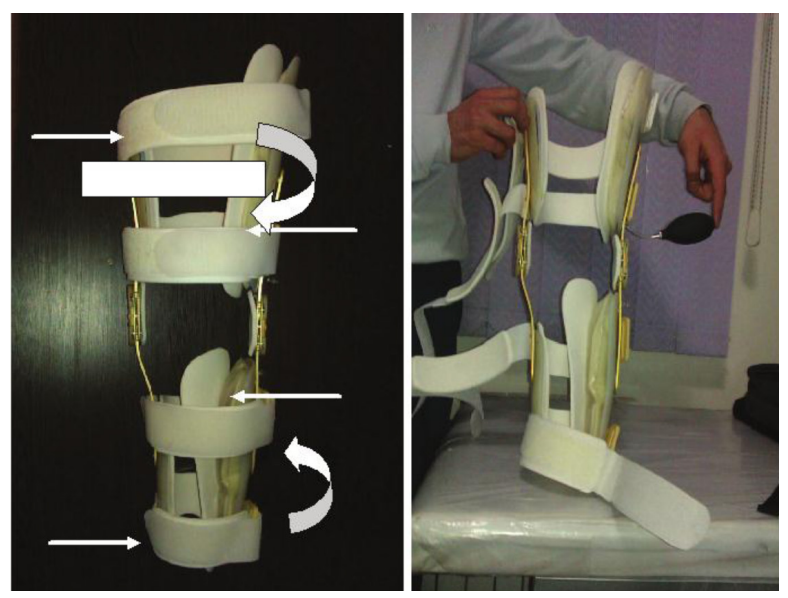

Figure 7: The custom-fitted knee unloader [29]. tion. This difference could be due to variant levels and severity of $\mathrm{OA}$ in the respective subjects. Consequently, more comprehensive studies should be done in this area by including all grades of OA. Even though this brace increased speed $(p=0.001)$ and also reduced knee ROM significantly $(p=0.002)$ it did not change the patient's cadence significantly $(p=0.504)$ [34].

\section{Assessment Summary}

The brace covers almost two-thirds of the femur and tibia when applied, providing longlever arms and a subsequently broader force distribution to control knee varus. In addition, proprioception is shown to be improved, and pain reduction, and these factors, plus greater knee stability, can help to increase the user's confidence. The use of a 4-point pressure system rather than a standard 3-point pressure system is also a relatively unique and an interesting alternative [34].

\section{Cherian JJ et al /rehabilitator brace}

\section{Design and Structure}

This brace was designed and constructed by Cherian JJ et al. in 2014 and consists of a pneumatic joint unloading mechanism, active swing-assist cuffs which are flexible; elastic straps, (which provide more compliance) and two uprights made of a rigid composite material, (which provide mediolateral stability) (Figure 8). The pneumatic unloading is accomplished through strategically placed air bladders that are inflated until desired pressure is achieved. The user can increase or decrease this pressure according to the level of activity. In this way, the user begins the process with the loading at its greatest level and then unloads to suit, making this design somewhat different from previous types. Swing assist is accomplished through using an elastic cord that is embedded within the hinge of the brace, thereby providing a dampening effect during knee flexion and an active swing assist during terminal stance. At the end of swing phase, the 


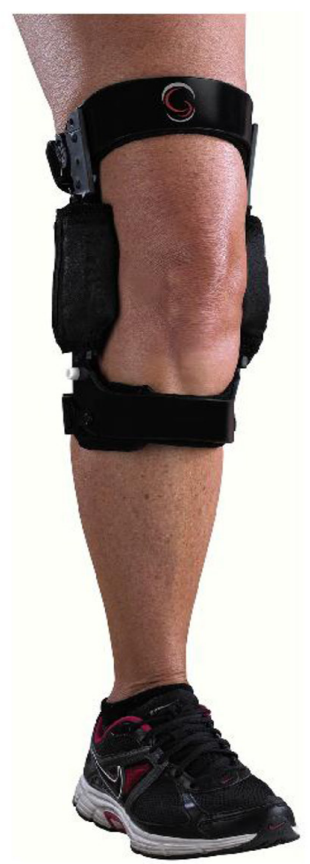

Figure 8: pneumatic brace with extension assist [30].

hamstrings have to work concentrically and increase the speed of knee extension; under loading, the quadriceps have to work eccentrically against the extension assist bands. Most adult users could employ assist bands that stretch at $5 \mathrm{lbs} /$ in displacement; larger users could employ bands with $7 \mathrm{lbs} /$ in of displacement [35].

User Outcomes

This brace can reduce pain (before brace: 4.7 point, after brace: 2.8 point) and improve the function in patients with severe OA (22.4 s TUG and timed to up tests improvement significantly, $\mathrm{P}=0.007$ ); also the timed stair climb test showed the improvement of $7.8 \mathrm{~s}$ $(\mathrm{P}=0.007)$. Quadriceps muscle strength improved 54\% (before brace: $19.6 \mathrm{ft} .1 \mathrm{~b} \mathrm{BW} / 100$, after brace: $28.1 \mathrm{ft} .1 \mathrm{~b} \mathrm{BW} / 100, \mathrm{P}=0.022$ ), and an improvement was also seen in hamstring muscle strength (almost 27.7\%) (before brace: 17.3 ft.lb BW/100, after brace: 21.5 ft.lb BW/100 $(\mathrm{P}=0.0016)$ compared with no orthosis [35].
Assessment Summary

Users find this brace comfortable and ergonomic. This type of pneumatic brace with extension assist is light and may be useful in delaying or cancelling the need for knee replacement surgery [35].

\section{Laroche et al / ODRA brace Design and Structure}

The ODRA brace was made by Lorache and colleagues in 2014 and brace consists of a rigid shell on the thigh and lower leg sections, with struts, external and internal hinges (Figure 9).

Each hinge of the brace is linked to a pinion rack system that slides into a slotted hole. Each hinge can move along the vertical and transverse plane, thereby initiating vertical and horizontal displacement of the medial and lateral hinges that subsequently reduce the force on the medial compartment, and also increasing both lateral rotation of the foot, and creating a knee valgus moment. When the knee is extended in the stance phase, the internal

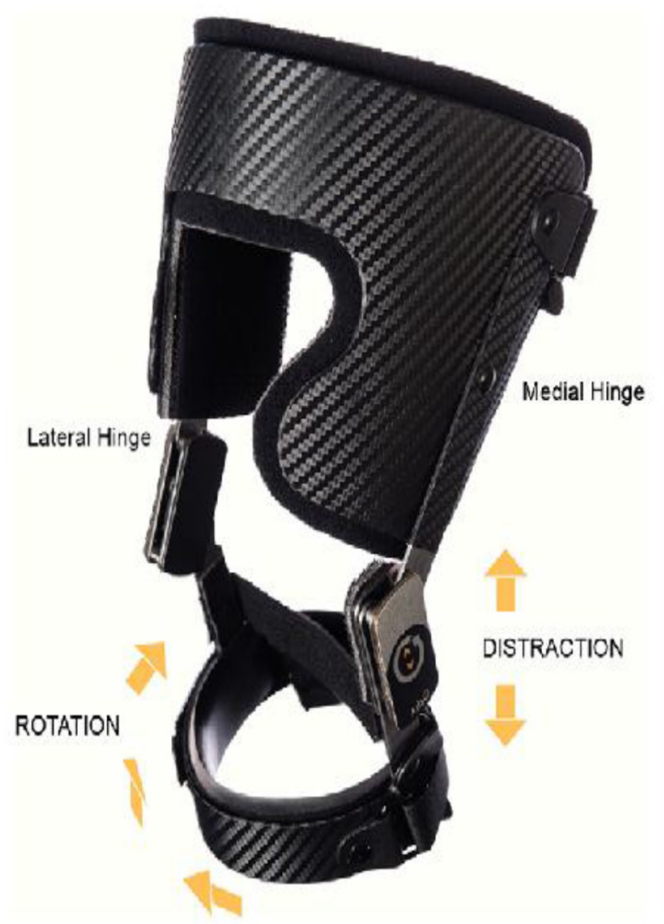

Figure 9: The distraction-rotation mechanism of the ODRA brace [31]. 
hinge causes the brace to extend and creates a displacement between the tibia and femur, effectively promoting knee valgus. The lateral hinge causes the joint to move backwards, thereby imparting external rotation of the foot.

This brace induces valgus and rotation in the stance phase only when the leg is straight and extended and it does not have any effects when knee is flexed. Therefore, it has its maximum effect at the beginning and end of the stance phase, with no effects in the swing phase [36, 37].

\section{User Outcomes}

The ODRA brace has been shown to improve walking speed significantly ( $>10 \%)$, as well as an immediate reduction in the KAM $(8 \% \mathrm{p}<0.01)$ which improved to $22 \%(\mathrm{p}<0.01)$ after 5 weeks of wearing the brace. Pain also reportedly decreased, on a VAS scale (first week: $1.1 \pm 6.3$, fifth week: $1.3 \pm 3.0, \mathrm{P}<0.01)$. WOMAC pain, function and stiffness were improved $30 \%(\mathrm{P}<0.001)$ and foot progression angle was also improved. Significant reductions in the corresponding stance phase percentiles were reported, but no significant differences in internal and external rotation of knee or step width were observed [36, 37].

Assessment Summary

This brace improved proprioception and cocontraction, which could be due to the corresponding reduction in pain during use. 17 out of 20 users were satisfied with this brace, and its effect on their OA symptoms. The ODRA brace is custom-made and, probably due to have rigid shells, it is heavier than those made from neoprene $[36,37]$.

\section{Karimi et al (b)/un-named brace Design and Structure}

The brace was made by Karimi and colleagues in 2015 and includes four elastic straps, an adjustable internal and external shell, and an adjustable lateral screw [38].

\section{User Outcomes}

The use of this brace slightly decreased the joint contact forces, including external forces (ground reaction force and body weight) and internal forces (muscle, ligament and joint capsule tensions), but not to any significant extent. This reduction may have been related to reduced muscle activity around the knee joint. No significant alteration to sagittal plane knee $\mathrm{ROM}$ was seen $(\mathrm{p}=0.477)$. The overall knee alignment was improved, but there is no significant changes in speed, stride length, or cadence reported. In addition, no significant differences were noted between the vertical and mediolateral forces acting on the lower limbs during walking (at $\mathrm{p}=0>05$ and $\mathrm{p}=0.29$ respectively) [38].

\section{Assessment Summary}

Users felt comfortable when walking with this brace, with displacement between the brace and the limb being negligible. The implementation of a double-shell design enabled a close, intimate fit between the limb and the brace to be acquired, increasing both comfort and stability [38].

\section{Discussion}

The number of people suffering from knee $\mathrm{OA}$ is increasing, as populations become older and obesity increases. In people without OA, the average adduction moment is 3.3 times body weight $\times$ height, while in patients with medial knee OA this figure increases to 4.2 times body weight $\times$ height. In addition, the KAM is higher than that in normal individuals by approximately $25 \%$ (almost $1 \%$ of body weight $\times$ height) $[11,39]$. An increased KAM leads to increase in forces in the medial aspect of the knee during walking [39, 40], with a $20 \%$ increase in the adduction moment leading to a subsequent increase and progression of existing OA [41].

Numerous studies have indicated that the correct use of an appropriate knee brace in subjects with OA can produce an increased valgus moment around the knee joint, which counteracts and resists excessive varus loading on the medial compartment of the knee. Previous studies have also shown that lower limb malalignment and an increase in adduction moment cause pain and reduce levels of mobility in affected subjects [10, 42]. Furthermore, recent studies have demonstrated that for each $1 \mathrm{Nm}$ increase in valgus moments created by a brace, a corresponding $3 \%$ reduc- 
tion in adduction moment is created and a subsequent $1 \%$ reduction in loads on the medial compartment of the knee is the result $[18,24$, $33,36,43-46]$. Therefore, it would seem logical to state that the first and most important goal in designing knee braces is to reduce the KAM in order to prevent the progression of $\mathrm{OA}$, by reducing the load on the medial compartment of the knee and thereby as a consequence reducing the corresponding levels of pain $[21,47]$.

This study clearly showed that most braces reduce the knee adduction moment, although the amount of reduction varies between each brace. For example, Johnson et al. in 2012 reported an mean reduction in the KAM of $48 \%$, but in this case all the test subjects had less than $10^{\circ}$ varus and were only classified as grade 2 or 3 on Kellgren-Lawrence scale for OA classification [31]. Conversely, similar studies have also reported a reduction of $7 \%$ and $10 \%$ in the KAM during walking with a brace in situ [30, 34]. Della Croce et al. reported a $6.6 \%$ reduction in KAM moment whilst the air bladders within the brace were deflated compared with a $26 \%$ reduction when they were inflated to a constant pressure of 7 Psi [33]. Geesbaak reported that their knee brace decreased the adduction moment, although it is not significant in the case in question, this reduction would apparently increase in subjects with more severe OA [28]. Laroche reported an immediate $22 \%$ reduction in the adduction moment by the use of their knee brace and a further $8 \%$ decrease after 5 further weeks of use [36].

These differences in the associated with the reduction of the KAM appear to relate to the design and structure of each particular brace, its characteristics and adjustability during use, and its level of comfort and compliance, in addition to the specific methodology. Arazpour, for example, reported that their brace reduced the KAM by almost 7\%, whilst previous studies reported even more reduction. These differences could be associated with the grade of OA that the respective subjects presented
[34]. Thus, it would be more useful to conduct more comprehensive studies in this field by including all grades of $\mathrm{OA}$, and rate comfort, compliance and device usability accordingly. Studies also suggest that the pain reduction and functional improvement in people with $\mathrm{OA}$ are related to the levels of KAM reduction that can be acquired, and then subsequent reduction in the forces that affect the medial knee compartment [24, 26, 28, 34, 36, 43]. In addition, the consequent reduction in pain can result in improved levels of proprioception and muscular control [34, 36].

Knee OA is associated with joint laxity and instability in the frontal and mediolateral planes [48-51]. In people with OA, joint instability is compensated for increased cocontraction of the appropriate muscles [51]. Forces exerted on the medial compartment and adduction moment reduction (even if reduction is not significant) [28] will result in pain reduction and function improvement that cause the muscles co-contraction and the proprioception rise. This will ultimately increase the stability of the knee joint. The reviewed studies in this article, only 6 studies assessed patient's pain and function, and all of them reported significant pain reduction and functional improvement [28, 30, 31, 35, 36, 52]. For example, Lorache et al. reported that pain was $6.3 \pm 1.1$ in the first week and $3.0 \pm 1.3$ in the fifth week $(\mathrm{P}<0.01)$, also WOMAC scores decreased almost 30\%, which were reported as a significant decrease in pain and improvement in functional activity, achieved through proprioception improvement and co-contraction [36]. Knopf et al. showed that pain could be reduced from $6.4 \pm 1.7$ to $3.3 \pm 1.9$ after 4 weeks of brace use $(\mathrm{P} \leq 0.01)$ [30].

Pain will affect both kinetic and kinematic gait [18], and studies have shown that OArelated pain reduces walking speed, range of motion, cadence, stride length, and increases the adduction moment during walking [28]. The use of a correctly fitted brace can help to reduce the KAM and associated levels of 
OA pain, and as a consequence, it should ultimately lead to improvements in the gait and mobility [53]. However, the effects of each particular brace on factors such as the range of knee motion differ, due in all likelihood to the specific designs associated with each brace. For example, the results of Geesbaak's study showed that their brace indeed restrict full knee extension, leading to a corresponding decrease in the knee range of motion and an associated reduction in stride length [28]. Arazpour by contrast reported an increase in the range of motion when their brace was used, with before and after figures of $44^{\circ}$ and $48^{\circ}$ respectively [34]. Walking speed in particular can be affected by pain related to OA in the medial compartment; the correct use of an appropriate brace will reduce pain and potentially increase walking speed and mobility $[28,30]$. Almost all of the studies collated here reported a significant improvement in walking speed when the brace was used [28, 30, 31, 34, 38]. For example, Knopf et al. demonstrated that the walking speed of a user subject could increase from $1.27 \mathrm{~m} / \mathrm{s}$ to $1.36 \mathrm{~m} / \mathrm{s}(\mathrm{p} \leq 0.01)$ [30]. In addition, Gaasbeek also reported an increase in walking speed, with corresponding reductions in the levels of pain [28]. Similarly, Lorache reported increases in walking speed of more than $10 \%$ [36].

Stride length was a parameter that varied considerably between the brace usage. Gaasbeek et al reported a reduction in stride length due to a decrease in the range of motion of the knee [28] whilst Knopf et al. reported a significant increase in the stride length on the affected side (from $0.71 \mathrm{~m}$ to $0.73 \mathrm{~m}$ ) and a significant decrease on the unaffected side (from 0.75 to $0.73 \mathrm{~m}$ ) [30]. Furthermore, Karimi et al. reported that the stride length remained unchanged by the use of their brace [54].These differences would again appear to reflect different basic designs for each brace. It should be noted however that use of a brace is not always the problem free; along with issues such as compliance, and comfort, and cosmetics, one of the defects on some braces noted here is knee flexion reduction in swing phase, which can reduce both stride length and foot-to-ground clearance $[26,28]$. In addition, it should also be noted that most studies use only small sample sizes, and to take place for a more rigorous evaluation, numbers of participants need to increase in future studies

\section{Limitations of Current Knee Ortho- ses}

An optimal knee brace design would be light, easy to put on and take off. However, to achieve its functional goals, a typical knee brace needs to incorporate mechanisms and structures that can reduce patient compliance over time. For example, one study showed that $42 \%$ of patients stopped using their brace during the first few days, with this number increasing to $64 \%$ after three months [55]. However, the use of a brace may be in OA treatment, if it is not worn, then it would not help, and this feature of treating affected subjects with a brace is clearly problematic $[55,56]$. If a brace is large, and inconvenient, it probably would not be used, even if technically it is sound [12, 23, 57]. In addition, braces with relatively poor cosmetics may also be rejected, and skin irritation may also lead to non-use $[12,47,58,59]$. With these factors in mind, four pneumatic braces noted in this study have been made of lightweight materials such as neoprene $[12,31,33,35]$. In addition, the brace presented by Karimi was also deemed to be lightweight and comfortable, despite not being pneumatic in the design [38]. Other studies did not appear to report factors such as weight and comfort. Further to these observations, we recommend that basic factors related to convenience, comfort and usability of the braces should be high priorities, without necessarily changing their specific mechanisms of usage $[12,28,31,60]$. In addition, one of the main challenges for brace designers is achieving a close fit throughout the gait cycle that does not require any consistent adjustment 
during usage [12, 59].

\section{Conclusion}

The first and most important goal in designing a brace is to reduce the KAM in order to prevent the progression of OA. OA reduces walking speed, the range of motion, cadence, stride length, and increases adduction moment during walking. This study clearly showed that most braces reduce the adduction moment; however, the amount of reduction is different in various studies. In recent years, many efforts have been made to make braces lighter to improve acceptability. However, there are still limitations in designs. New orthoses that overcome the limitations of previous models and also help improve OA symptom are still need, and greater numbers of subjects are also required. We would also recommend that activity monitors be employed in future studies, as patient compliance over time is clearly a factor in this type of treatment.

\section{Acknowledgment}

The authors would like to acknowledge Mr. Mehrdad Davoodi specialist in biomechanical engineering for his valuable contributions.

\section{Conflict of Interest}

None

\section{References}

1. Health NIo, Health UDo, Services H. National Institute of Arthritis and Musculoskeletal and Skin Disease; Fact Sheet: Osteoarthritis. Bethesda, MD: National Institute of Health; 2010.

2. Losina E, Walensky RP, Reichmann WM, Holt HL, Gerlovin $\mathrm{H}$, Solomon $\mathrm{DH}$, et al. Impact of obesity and knee osteoarthritis on morbidity and mortality in older Americans. Ann Intern Med. 2011;154:21726. doi: 10.7326/0003-4819-154-4-20110215000001. PubMed PMID: 21320937; PubMed PMCID: PMC3260464.

3. Lachance L, Sowers MF, Jamadar D, Hochberg M. The natural history of emergent osteoarthritis of the knee in women. Osteoarthritis Cartilage. 2002;10:849-54. PubMed PMID: 12435329.

4. Horlick SG, Loomer RL. Valgus knee bracing for medical gonarthrosis. Clin J Sport Med. 1993;3:2515.

5. Tanamas S, Hanna FS, Cicuttini FM, Wluka AE, Berry
P, Urquhart DM. Does knee malalignment increase the risk of development and progression of knee osteoarthritis? A systematic review. Arthritis Rheum. 2009;61:459-67. doi: 10.1002/art.24336. PubMed PMID: 19333985.

6. Sharma L, Dunlop D, Andriacchi T, Hayes K, Song J, Cahue S, et al., editors. The adduction moment and knee osteoarthritis (OA), a longitudinal study. Arthritis and Rheumatism. 2003;48(9 Supple):S452.

7. Tetsworth K, Paley D. Malalignment and degenerative arthropathy. Orthop Clin North Am. 1994;25:367-77. PubMed PMID: 8028880.

8. Vincent KR, Conrad BP, Fregly BJ, Vincent HK. The pathophysiology of osteoarthritis: a mechanical perspective on the knee joint. PM R. 2012;4:S3-9. doi: 10.1016/j.pmrj.2012.01.020. PubMed PMID: 22632700; PubMed PMCID: PMC3635670.

9. Andriacchi TP. Dynamics of knee malalignment. Orthop Clin North Am. 1994;25:395-403. PubMed PMID: 8028883.

10. Sharma L, Song J, Felson DT, Cahue S, Shamiyeh $\mathrm{E}$, Dunlop DD. The role of knee alignment in disease progression and functional decline in knee osteoarthritis. JAMA. 2001;286:188-95. PubMed PMID: 11448282.

11. Schipplein OD, Andriacchi TP. Interaction between active and passive knee stabilizers during level walking. J Orthop Res. 1991;9:113-9. doi: 10.1002/ jor.1100090114. PubMed PMID: 1984041.

12. Stamenovic D, Kojic M, Stojanovic B, Hunter D. Pneumatic osteoarthritis knee brace. J Biomech Eng. 2009;131:045001. doi: 10.1115/1.3072890. PubMed PMID: 19275449.

13. Zhang W, Moskowitz RW, Nuki G, Abramson S, Altman $\mathrm{RD}$, et al. OARSI recommendations for the management of hip and knee osteoarthritis, Part II: OARSI evidence-based, expert consensus guidelines. Osteoarthritis Cartilage. 2008;16:137-62. doi: 10.1016/j. joca.2007.12.013. PubMed PMID: 18279766.

14. Zhang W, Moskowitz RW, Nuki G, Abramson S, Altman $\mathrm{RD}$, Arden $\mathrm{N}$, et al. OARSI recommendations for the management of hip and knee osteoarthritis, part I: critical appraisal of existing treatment guidelines and systematic review of current research evidence. Osteoarthritis Cartilage. 2007;15:981-1000. doi: 10.1016/j.joca.2007.06.014. PubMed PMID: 17719803.

15. Cheng OT, Souzdalnitski D, Vrooman B, Cheng J. Evidence-based knee injections for the management of arthritis. Pain Med. 2012;13:740-53. doi: 10.1111/j.1526-4637.2012.01394.x. PubMed PMID: 22621287; PubMed PMCID: PMC3376243.

16. Todd PA, Clissold SP. Naproxen. A reappraisal of its pharmacology, and therapeutic use in rheumatic diseases and pain states. Drugs. 1990;40:91-137. PubMed PMID: 2202585.

17. Chuang SH, Huang MH, Chen TW, Weng MC, Liu $\mathrm{CW}$, Chen $\mathrm{CH}$. Effect of knee sleeve on static and dynamic balance in patients with knee osteoarthritis. Kaohsiung J Med Sci. 2007;23:405-11. doi: 10.1016/S0257-5655(07)70004-4. PubMed PMID: 


\section{7.}

18. Divine JG, Hewett TE. Valgus bracing for degenerative knee osteoarthritis: relieving pain, improving gait, and increasing activity. Phys Sportsmed. 2005;33:40-6. doi: 10.3810/psm.2005.02.48. PubMed PMID: 20086350.

19. Haim A, Rozen N, Dekel S, Halperin N, Wolf A. Control of knee coronal plane moment via modulation of center of pressure: a prospective gait analysis study. J Biomech. 2008;41:3010-6. doi: 10.1016/j. jbiomech.2008.07.029. PubMed PMID: 18805527.

20. Pollo FE, Jackson RW. Knee bracing for unicompartmental osteoarthritis. J Am Acad Orthop Surg. 2006;14:5-11. PubMed PMID: 16394162.

21. Otis J, Backus S, Campbell D, Furman G, Garrison G, Warren R, et al. Valgus bracing for knee osteoarthritis: A biomechanical and clinical outcome study. Gait Posture. 2000;11:116-17.

22. Felson DT, Lawrence RC, Dieppe PA, Hirsch R, Helmick CG, Jordan JM, et al. Osteoarthritis: new insights. Part 1: the disease and its risk factors. Ann Intern Med. 2000;133:635-46. PubMed PMID: 11033593.

23. Basford JR, Johnson SJ. Form may be as important as function in orthotic acceptance: a case report. Arch Phys Med Rehabil. 2002;83:433-5. PubMed PMID: 11887129.

24. Jones RK, Nester CJ, Richards JD, Kim WY, Johnson DS, Jari $S$, et al. A comparison of the biomechanical effects of valgus knee braces and lateral wedged insoles in patients with knee osteoarthritis. Gait Posture. 2013;37:368-72. doi: 10.1016/j.gaitpost.2012.08.002. PubMed PMID: 22920242.

25. Felson DT, Naimark A, Anderson J, Kazis L, Castelli W, Meenan RF. The prevalence of knee osteoarthritis in the elderly. The Framingham Osteoarthritis Study. Arthritis Rheum. 1987;30:914-8. PubMed PMID: 3632732.

26. Richards JD, Sanchez-Ballester J, Jones RK, Darke N, Livingstone $B^{\star} N$. A comparison of knee braces during walking for the treatment of osteoarthritis of the medial compartment of the knee. J Bone Joint Surg Br. 2005;87:937-9. doi: 10.1302/0301-620X.87B7.16005. PubMed PMID: 15972906.

27. Kirkley A, Webster-Bogaert S, Litchfield R, Amendola A, MacDonald S, McCalden R, et al. The effect of bracing on varus gonarthrosis. J Bone Joint Surg Am. 1999;81:539-48. PubMed PMID: 10225800.

28. Gaasbeek RD, Groen BE, Hampsink B, Van Heerwaarden RJ, Duysens J. Valgus bracing in patients with medial compartment osteoarthritis of the knee. A gait analysis study of a new brace. Gait Posture. 2007;26:3-10. doi: 10.1016/j.gaitpost.2006.07.007. PubMed PMID: 16962329.

29. Van Heerwaarden R, Gaasbeek R, Plitz W. A new valgus brace for medial knee osteoarthritis. A short term patient evaluation study with the Softec OA brace. Med-Orthopädische Technik. 2005;57:65.

30. Schmalz T, Knopf E, Drewitz H, Blumentritt S. Analysis of biomechanical effectiveness of valgus-inducing knee brace for osteoarthritis of knee. J Rehabil Res Dev. 2010;47:419-29. PubMed PMID: 20803386.

31. Johnson AJ, Starr R, Kapadia BH, Bhave A, Mont MA. Gait and clinical improvements with a novel knee brace for knee OA. J Knee Surg. 2013;26:1738. doi: 10.1055/s-0032-1327452. PubMed PMID: 23288742.

32. Esrafilian A, Karimi MT, Eshraghi A. Design and evaluation of a new type of knee orthosis to align the mediolateral angle of the knee joint with osteoarthritis. Adv Orthop. 2012;2012:104927. doi: 10.1155/2012/104927. PubMed PMID: 22577565; PubMed PMCID: PMC3345217.

33. Della Croce U, Crapanzano F, Li L, Kasi PK, Patritti $\mathrm{BL}$, Mancinelli $\mathrm{C}$, et al. A preliminary assessment of a novel pneumatic unloading knee brace on the gait mechanics of patients with knee osteoarthritis. $P M \& R$. 2013;5:816-24. doi: 10.1016/j.pmrj.2013.06.008. PubMed PMID: 23810812.

34. Arazpour M, Hutchins SW, Bani MA, Curran S, Aksenov $A$. The influence of a bespoke unloader knee brace on gait in medial compartment osteoarthritis: a pilot study. Prosthet Orthot Int. 2014;38:379-86. doi: 10.1177/0309364613504780. PubMed PMID: 24532004.

35. Cherian JJ, Bhave A, Kapadia BH, Starr R, McElroy MJ, Mont MA. Strength and Functional Improvement Using Pneumatic Brace with Extension Assist for End-Stage Knee Osteoarthritis: A Prospective, Randomized trial. J Arthroplasty. 2015;30:747-53. doi: 10.1016/j.arth.2014.11.036. PubMed PMID: 25499679.

36. Laroche D, Morisset C, Fortunet C, Gremeaux V, Maillefert JF, Ornetti P. Biomechanical effectiveness of a distraction-rotation knee brace in medial knee osteoarthritis: preliminary results. Knee. 2014;21:7106. doi: 10.1016/j.knee.2014.02.015. PubMed PMID: 24642050.

37. Ornetti P, Fortunet C, Morisset C, Gremeaux V, Maillefert JF, Casillas JM, et al. Clinical effectiveness and safety of a distraction-rotation knee brace for medial knee osteoarthritis. Ann Phys Rehabil Med. 2015;58:126-31. doi: 10.1016/j.rehab.2015.03.004. PubMed PMID: 26004814.

38. Karimi MT, Saljoghian P, Fatoye F. The Effectiveness of a Newly Designed Orthosis on Knee Contact Forces in Subjects with Knee Osteoarthritis. Ortop Traumatol Rehabil. 2015;17:259-63. doi: 10.5604/15093492.1162425. PubMed PMID: 26248627.

39. Hurwitz DE, Ryals AB, Case JP, Block JA, Andriacchi TP. The knee adduction moment during gait in subjects with knee osteoarthritis is more closely correlated with static alignment than radiographic disease severity, toe out angle and pain. $J$ Orthop Res. 2002;20:101-7. doi: 10.1016/S07360266(01)00081-X. PubMed PMID: 11853076.

40. Miyazaki T, Wada M, Kawahara H, Sato M, Baba $H$, Shimada S. Dynamic load at baseline can predict radiographic disease progression in medial compartment knee osteoarthritis. Ann Rheum Dis. 2002;61:617-22. PubMed PMID: 12079903; PubMed 
PMCID: PMC1754164

41. Kemp G, Crossley KM, Wrigley TV, Metcalf BR, Hinman RS. Reducing joint loading in medial knee osteoarthritis: shoes and canes. Arthritis Rheum. 2008;59:609-14. doi: 10.1002/art.23578. PubMed PMID: 18438932.

42. Amin S, Luepongsak N, McGibbon CA, LaValley MP, Krebs DE, Felson DT. Knee adduction moment and development of chronic knee pain in elders. Arthritis Rheum. 2004;51:371-6. doi: 10.1002/art.20396. PubMed PMID: 15188321.

43. Arazpour M, Ahmadi Bani M, Hutchins SW, Jones RK, Habibi Babadi M. Frontal plane corrective ability of a new unloader orthosis for medial compartment of the knee. Prosthet Orthot Int. 2013;37:481-8. doi: 10.1177/0309364613478964. PubMed PMID: 23471227.

44. Esrafilian A, Karimi MT, Amiri P, Fatoye F. Performance of subjects with knee osteoarthritis during walking: differential parameters. Rheumatol Int. 2013;33:1753-61. doi: 10.1007/s00296-012-2639-2. PubMed PMID: 23292190.

45. Moyer RF, Birmingham TB, Dombroski CE, Walsh RF, Leitch KM, Jenkyn TR, et al. Combined effects of a valgus knee brace and lateral wedge foot orthotic on the external knee adduction moment in patients with varus gonarthrosis. Arch Phys Med Rehabil. 2013;94:103-12. doi: 10.1016/j.apmr.2012.09.004. PubMed PMID: 22995151.

46. Arazpour M, Notarki TT, Salimi A, Bani MA, Nabavi $H$, Hutchins SW. The effect of patellofemoral bracing on walking in individuals with patellofemoral pain syndrome. Prosthet Orthot Int. 2013;37:465-70. doi: 10.1177/0309364613476535. PubMed PMID: 23436695 .

47. Hewett TE, Noyes FR, Barber-Westin SD, Heckmann TP. Decrease in knee joint pain and increase in function in patients with medial compartment arthrosis: a prospective analysis of valgus bracing. Orthopedics. 1998;21:131-8. PubMed PMID: 9507265.

48. Fitzgerald GK. Therapeutic exercise for knee osteoarthritis: considering factors that may influence outcome. Eura Medicophys. 2005;41:163-71. PubMed PMID: 16200033.

49. Lewek MD, Rudolph KS, Snyder-Mackler L. Control of frontal plane knee laxity during gait in patients with medial compartment knee osteoarthritis. Osteoarthritis Cartilage. 2004;12:745-51. doi: 10.1016/j. joca.2004.05.005. PubMed PMID: 15325641; PubMed PMCID: PMC3123521.

50. Sharma L, Lou C, Felson DT, Dunlop DD, KirwanMellis G, Hayes KW, et al. Laxity in healthy and osteoarthritic knees. Arthritis Rheum. 1999:42:861-70. doi: $\quad 10.1002 / 1529-0131(199905) 42: 5<861:: A I D-$
ANR4>3.0.C0;2-N. PubMed PMID: 10323441.

51. Ramsey DK, Briem K, Axe MJ, Snyder-Mackler L. A mechanical theory for the effectiveness of bracing for medial compartment osteoarthritis of the knee. J Bone Joint Surg Am. 2007;89:2398-407. doi: 10.2106/JBJS.F.01136. PubMed PMID: 17974881; PubMed PMCID: PMC3217466.

52. Arazpour M, Bani MA, Maleki M, Ghomshe FT, Kashani RV, Hutchins SW. Comparison of the efficacy of laterally wedged insoles and bespoke unloader knee orthoses in treating medial compartment knee osteoarthritis. Prosthet Orthot Int. 2013;37:507. doi: 10.1177/0309364612447094. PubMed PMID: 22864510.

53. Pagani $\mathrm{CH}$, Bohle C, Potthast W, Bruggemann GP. Short-term effects of a dedicated knee orthosis on knee adduction moment, pain, and function in patients with osteoarthritis. Arch Phys Med Rehabil. 2010;91:1936-41. doi: 10.1016/j.apmr.2010.09.003. PubMed PMID: 21112437.

54. Karimi MT, Saljoghian P, Fatoye F. The Effectiveness of a Newly Designed Orthosis on Knee Contact Forces in Subjects with Knee Osteoarthritis. Ortop Traumatol Rehabil. 2015;17:259-63. doi: 10.5604/15093492.1162425. PubMed PMID: 26248627.

55. Brouwer RW, Van Raaij TM, Verhaar JA, Coene LN, Bierma-Zeinstra SM. Brace treatment for osteoarthritis of the knee: a prospective randomized multicentre trial. Osteoarthritis Cartilage. 2006;14:777-83. doi: 10.1016/j.joca.2006.02.004. PubMed PMID: 16563810.

56. Gross KD. Device use: walking AIDS, braces, and orthoses for symptomatic knee osteoarthritis. Clin Geriatr Med. 2010;26:479-502. doi: 10.1016/j. cger.2010.03.007. PubMed PMID: 20699167.

57. Krohn K. Footwear alterations and bracing as treatments for knee osteoarthritis. Curr Opin Rheumatol. 2005;17:653-6. PubMed PMID: 16093848.

58. Barnes CL, Cawley PW, Hederman B. Effect of CounterForce brace on symptomatic relief in a group of patients with symptomatic unicompartmental osteoarthritis: a prospective 2-year investigation. $A m \mathrm{~J}$ Orthop (Belle Mead NJ). 2002;31:396-401. PubMed PMID: 12180625.

59. Matsuno H, Kadowaki KM, Tsuji H. Generation II knee bracing for severe medial compartment osteoarthritis of the knee. Arch Phys Med Rehabil. 1997;78:745-9. PubMed PMID: 9228878.

60. Dillon CF, Rasch EK, Gu Q, Hirsch R. Prevalence of knee osteoarthritis in the United States: arthritis data from the Third National Health and Nutrition Examination Survey 1991-94. J Rheumatol. 2006;33:22719. PubMed PMID: 17013996. 